\title{
Neuroimaging predictors of treatment response in anxiety disorders
}

Lisa M Shin ${ }^{1,2^{*}}$, F Caroline Davis ${ }^{1,2}$, Michael B VanElzakker ${ }^{1,2}$, Mary K Dahlgren ${ }^{1,2}$ and Stacey J Dubois ${ }^{1,2}$

\begin{abstract}
Although several psychological and pharmacological treatment options are available for anxiety disorders, not all patients respond well to each option. Furthermore, given the relatively long duration of adequate treatment trials, finding a good treatment fit can take many months or longer. Thus, both clinicians and patients would benefit from the identification of objective pre-treatment measures that predict which patients will best respond to a given treatment. Recent studies have begun to use biological measures to help predict symptomatic change after treatment in anxiety disorders. In this review, we summarize studies that have used structural and functional neuroimaging measures to predict treatment response in obsessive-compulsive disorder (OCD), posttraumatic stress disorder (PTSD), generalized anxiety disorder (GAD), and social anxiety disorder (SAD). We note the limitations of the current studies and offer suggestions for future research. Although the literature is currently small, we conclude that pre-treatment neuroimaging measures do appear to predict treatment response in anxiety disorders, and future research will be needed to determine the relative predictive power of neuroimaging measures as compared to clinical and demographic measures.
\end{abstract}

Keywords: Social anxiety disorder, Obsessive-compulsive disorder, Posttraumatic stress disorder, Generalized anxiety disorder, Amygdala, Medial prefrontal cortex, Anterior cingulate cortex, Orbitofrontal cortex, fMRI, PET

\section{Review}

Anxiety disorders are highly prevalent [1] and are associated with occupational disability and increased family burden [2-4]. Although psychological and pharmacological treatments are available, they are not always effective. For example, a recent naturalistic study of obsessive-compulsive disorder (OCD) revealed that only approximately two-thirds of individuals taking serotonin reuptake inhibitors (SRIs) considered their symptoms very much or much improved [5]. The percentage of individuals responding to pharmacotherapy appears to be even lower in posttraumatic stress disorder (PTSD) [6]. Although cognitive-behavioral therapies are moderately effective in the treatment of anxiety disorders, there appears to be room for improvement [7-9], perhaps especially in the case of panic disorder and generalized anxiety disorder (GAD) [8].

\footnotetext{
* Correspondence: Lisa.Shin@tufts.edu

'Department of Psychology, Tufts University, Medford, MA, USA

${ }^{2}$ Department of Psychiatry, Massachusetts General Hospital, Charlestown, MA, USA
}

\section{Biomed Central}

(C) 2013 Shin et al.; licensee BioMed Central Ltd. This is an Open Access article distributed under the terms of the Creative Commons Attribution License (http://creativecommons.org/licenses/by/2.0), which permits unrestricted use, distribution, and reproduction in any medium, provided the original work is properly cited.
Given the variability in treatment response, it would be beneficial to determine whether measures obtained before treatment could help clinicians predict symptomatic change in response to a given treatment. Several clinical measures have been useful in this regard. For example, greater pre-treatment symptom severity has been associated with less favorable response to treatment in OCD [10], PTSD [11,12], social anxiety disorder (SAD) $[13,14]$, and in youth with anxiety disorders [15]. Other clinical variables have predicted a less favorable response to treatment, such as the presence of hoarding obsessions and compulsions [16] and comorbid personality disorders in OCD [17] and greater depression and avoidant personality traits in SAD [18].

Recent studies have begun to use biological measures to predict symptomatic change after treatment in anxiety disorders (e.g., [19-22]). Such measures are more objective and arguably more proximal to the neurobiological substrates of these disorders as compared to symptom severity measures. Structural and functional neuroimaging techniques yield such biological measures (e.g., regional cerebral metabolic rate for glucose [rCMRglu] in 
the anterior cingulate cortex $[\mathrm{ACC}])$ that can be examined for possible associations with treatment response. Here, we will review the findings of longitudinal studies that used pre-treatment structural and functional neuroimaging measures to predict treatment-related symptomatic change in anxiety disorders.

\section{Methodological considerations}

The studies reviewed below implemented a variety of different imaging techniques and data analytic approaches. Early studies tended to use positron emission tomography (PET) and fluorodeoxyglucose (FDG) to measure rCMRglu while patients rested with eyes open. Although such resting state studies are relatively easy to administer because they require no explicit cognitive task, they are also limited by a lack of control over the mental processes in which subjects engage during the radiotracer uptake period. This can lead to greater variability in the data, perhaps increasing the risk of type II errors (depending on the kinds of analyses used), as well as some difficulty interpreting the meaning of the rCMRglu findings. In general, PET-FDG imaging is also limited by relatively poor temporal resolution as rCMRglu data are typically averaged across long periods of time ( $\sim 30-45$ minutes).

Many older PET-FDG studies also used regionof-interest (ROI) based analyses in which researchers draw boundaries around brain regions based on structural anatomy, "extract" functional imaging data from those drawn regions, and submit the extracted data to external statistical software. One disadvantage of this technique is that it involves averaging functional imaging data across very large brain structures, increasing the risk of type II error if only a small portion of that large brain structure is actually important in the prediction of treatment response. More recent neuroimaging studies employ voxelwise analyses that can assess the relationship between brain activation (or gray matter volume) and treatment response at every voxel (e.g., $3 \mathrm{~mm} \times 3 \mathrm{~mm} \times 3 \mathrm{~mm}$ cube) in the brain. However, in order to complete such analyses, one must "normalize" or morph the functional (and/or structural) brain images to a standard brain template, which introduces some amount of error. In addition, voxelwise analyses involve conducting thousands of analyses (one per voxel) across the brain, so correction for multiple comparisons must be applied.

More recent studies have implemented functional magnetic resonance imaging (fMRI) to measure brain activation in response to cognitive and/or affective tasks. These types of studies afford more control over the cognitive state of the participant during scanning and, if well designed, allow for a more clear interpretation of the meaning of the imaging findings.
The methodological considerations described above apply to most functional neuroimaging studies, not just those assessing the prediction of treatment response. With regard to the latter specifically, researchers have used two different data analytic approaches. The first approach involves comparing treatment responders to non-responders on a pre-treatment neuroimaging measure (e.g., amygdala activation). For example, if treatment responders as a group were found to have lower pretreatment amygdala activation than non-responders, then lower amygdala activation would be considered to be predictive of a better response to treatment. This type of between-group analysis typically involves analysis of variance (ANOVA) or analysis of covariance (ANCOVA), and requires (1) a very clear and well-accepted definition of treatment response and (2) sufficiently large numbers of participants per group (responders and non-responders). Because the relative size of these post-treatment groups cannot be completely planned a priori, these studies should begin with a very large number of participants.

The second approach is to run a correlation (or a regression) between a continuous pre-treatment neuroimaging measure and a continuous measure of symptomatic improvement (e.g., symptom change score, percent improvement, or clinical global impression (CGI) improvement score). This type of analysis takes advantage of the inherent variability in both the imaging and treatment response data and is therefore likely to be more powerful than the between-group approach. Regression analyses also obviate the need to form responder and nonresponder groups and permit the investigation of multiple pre-treatment imaging (and non-imaging) variables in the prediction of treatment response. For example, baseline symptom severity and comorbidity measures (either categorical or continuous) can be entered into the regression along with pre-treatment imaging measures to predict symptom change scores. Several studies reviewed below included both types of approaches.

In the following text, we review studies that have assessed whether pre-treatment structural or functional neuroimaging measures can predict treatment response in OCD, PTSD, GAD, and SAD (See Table 1). (We were able to find no such studies of panic disorder or specific phobia). We did not include studies that assessed the change in neuroimaging measures with treatment as those studies address a different question.

\section{Obsessive-compulsive disorder (OCD)}

In contrast to other anxiety disorders, OCD appears to be marked by structural and functional abnormalities in thalamo-cortico-striatal loops. One neurocircuitry model of OCD $[23,24]$ posits that the striatum (caudate nucleus) functions abnormally, leading to inefficient gating in the thalamus. This leads to hyperactivity in the orbito- 
Table 1 Summary of Neuroimaging studies predicting treatment response in anxiety disorders

\begin{tabular}{|c|c|c|c|c|c|}
\hline Article & Disorder & Imaging & Treatment type & $\begin{array}{l}\text { Sample } \\
\text { sizes }\end{array}$ & Outcome mea \\
\hline $\begin{array}{l}\text { Swedo et al. } \\
\text { [32] }\end{array}$ & OCD & $\begin{array}{l}\text { PET-FDG: resting } \\
\text { state }\end{array}$ & $\begin{array}{l}\text { Clomipramine (dose and } \\
\text { duration not specified) }\end{array}$ & $\begin{array}{l}\text { OCD: } 18 \\
\text { Healthy: } 18\end{array}$ & $\begin{array}{l}\text { OCR Responders } \\
\text { reduction in OCF }\end{array}$ \\
\hline $\begin{array}{l}\text { Saxena et al. } \\
\text { [33] }\end{array}$ & OCD & $\begin{array}{l}\text { PET-FDG: resting } \\
\text { state }\end{array}$ & $\begin{array}{l}\text { Paroxetine (8-12 weeks; } \\
40 \text { mg/d max) }\end{array}$ & OCD: 20 & $\begin{array}{l}\text { YBOCS and CGI } \\
\geq 25 \% \text { reduction } \\
\text { and } C G \text { of much } \\
\text { or very much im } \\
\text { (11 R, } 9 \text { NR) }\end{array}$ \\
\hline $\begin{array}{l}\text { Saxena et al. } \\
\text { [34] }\end{array}$ & $\begin{array}{l}\text { OCD, } \\
\text { MDD, } \\
\text { OCD + } \\
\text { MDD }\end{array}$ & $\begin{array}{l}\text { PET-FDG: resting } \\
\text { state }\end{array}$ & $\begin{array}{l}\text { Paroxetine (8-12 weeks; } \\
30-60 \mathrm{mg} / \mathrm{d} \text { ) }\end{array}$ & $\begin{array}{l}\text { OCD: } 27 \\
\text { MDD: } 27 \\
\text { OCD + MDD: } \\
17\end{array}$ & YBOCS, HAM-D \\
\hline
\end{tabular}

\begin{tabular}{|c|c|c|c|c|c|}
\hline $\begin{array}{l}\text { Hendler } \\
\text { et al. [35] }\end{array}$ & OCD & $\begin{array}{l}\text { SPECT: symptom } \\
\text { provocation vs. } \\
\text { relax }\end{array}$ & $\begin{array}{l}\text { Sertraline ( } 6 \text { months; } \\
200 \text { mg/d max) }\end{array}$ & OCD: 26 & $\begin{array}{l}\text { YBOCS } \\
\text { reductio } \\
(13 \mathrm{R}, 1\end{array}$ \\
\hline $\begin{array}{l}\text { Rauch et al. } \\
\text { [36] }\end{array}$ & OCD & $\begin{array}{l}\text { PET-015: symptom } \\
\text { provocation vs. } \\
\text { neutral }\end{array}$ & $\begin{array}{l}\text { Fluvoxamine ( } 12 \text { weeks; } \\
300 \text { mg/d max) }\end{array}$ & OCD: 9 & YBOCS \\
\hline $\begin{array}{l}\text { Sanematsu } \\
\text { et al. [37] }\end{array}$ & OCD & $\begin{array}{l}\text { fMRI: symptom } \\
\text { provocation vs. } \\
\text { neutral }\end{array}$ & $\begin{array}{l}\text { Fluvoxamine ( } 12 \text { weeks; } \\
200 \text { mg/d max) }\end{array}$ & OCD: 17 & YBOCS \\
\hline
\end{tabular}

\begin{tabular}{|c|c|c|c|c|}
\hline $\begin{array}{l}\text { Ho Pian } \\
\text { et al. [38] }\end{array}$ & OCD & $\begin{array}{l}\text { SPECT: resting } \\
\text { state }\end{array}$ & $\begin{array}{l}\text { Fluvoxamine (12 weeks; } \\
300 \text { mg/d max) }\end{array}$ & OCD: 15 \\
\hline $\begin{array}{l}\text { Buchsbaum } \\
\text { et al. [39] }\end{array}$ & OCD & $\begin{array}{l}\text { PET-FDG: resting } \\
\text { state }\end{array}$ & $\begin{array}{l}\text { Risperidone or placebo } \\
\text { augmentation ( } 8 \text { weeks; } \\
3 \mathrm{mg} / \mathrm{d} \text { max) }\end{array}$ & $\begin{array}{l}\text { OCD: } 15 \\
\text { Risperidone: } \\
9 \text { Placebo: } 6\end{array}$ \\
\hline
\end{tabular}

YBOCS Responders: $\geq 25 \%$ reduction in YBOCS (7 R, $8 \mathrm{NR})$

YBOCS Responders: $\geq 25 \%$ reduction in YBOCS and/or CGI Improvement rating of very much improved or much improved (4 R, 5 NR)

Brody et al. OCD [40]

PET-FDG: resting state

Fluoxetine (10 weeks; $60 \mathrm{mg} / \mathrm{d}$ ) or group BT (10 weeks)

OCD: 27

Fluoxetine: 9

CBT: 18

Hoexter OCD $\quad \mathrm{mMRI}$ et al. [41]
YBOCS
Fluoxetine (12 weeks; $80 \mathrm{mg} / \mathrm{d}$ max) or group CBT (12 weekly sessions)

OCD: 29

Fluoxetine: 14 CBT: 15

\section{Findings}

Pre-treatment rCMRglu in the right ACC and right OFC was lower in clomipramine $\mathrm{R}$ vs. NR.

Lower pre-treatment rCMRglu in bilateral OFC predicted better response to paroxetine.

Greater pre-treatment rCMRglu in the caudate predicted greater improvement in OCD symptoms in the OCD groups. Lower rCMRglu in the amygdala predicted more improvement in MDD symptoms in MDD group and in all Ss combined. Greater pre-treatment rCMRglu in the medial frontal gyrus predicted improvement in MDD symptoms in all Ss.

$\mathrm{R}$ had lower pre-treatment perfusion during symptom provocation in dorsal/caudal ACC and higher perfusion in right caudate vs. NR.

Lower rCBF in OFC and higher rCBF in PCC predicted better response.

Pretreatment activation of right cerebellum and left superior temporal gyrus was positively correlated with YBOCS improvement.

Pre-treatment cerebellar and whole brain rCBF was significantly higher in R vs. NR.

Pre-treatment rCMRglu was lower in the striatum and higher in the ventral ACC in $R$ vs. NR.

Greater pre-treatment rCMRglu in the left OFC was associated with a better response to BT. In this same region, lower rCMRglu was associated with better response to fluoxetine.

Lower pre-treatment gray matter density in ventrolateral prefrontal cortex predicted better response to fluoxetine. Greater gray matter density in subgenual ACC predicted better response to CBT.

Greater pre-operative rCMRglu in posterior cingulate predicted greater improvement. 


\section{Table 1 Summary of Neuroimaging studies predicting treatment response in anxiety disorders (Continued)}

\begin{tabular}{|c|c|c|c|c|c|c|}
\hline $\begin{array}{l}\text { Van Laere } \\
\text { et al. [45] }\end{array}$ & OCD & $\begin{array}{l}\text { PET-FDG: resting } \\
\text { state }\end{array}$ & $\begin{array}{l}\text { Stimulation of anterior } \\
\text { capsule }\end{array}$ & $\begin{array}{l}\text { OCD: } 6 \\
\text { Controls: } 20\end{array}$ & YBOCS & $\begin{array}{l}\text { Greater pre-operative rCMRglu } \\
\text { in the subgenual ACC } \\
\text { predicted greater } \\
\text { improvement. }\end{array}$ \\
\hline $\begin{array}{l}\text { Bryant et al. } \\
\text { [68] }\end{array}$ & PTSD & $\mathrm{mMRI}$ & CBT (8 weekly sessions) & $\begin{array}{l}\text { PTSD: } 13 \\
\text { TENP: } 13 \\
\text { Healthy: } 13\end{array}$ & $\begin{array}{l}\text { CAPS Responders: no } \\
\text { longer met diagnostic } \\
\text { criteria ( } 7 \mathrm{R}, 6 \mathrm{NR})\end{array}$ & $\begin{array}{l}\text { Greater pre-treatment gray } \\
\text { matter density in the rACC } \\
\text { predicted greater } \\
\text { improvement. }\end{array}$ \\
\hline $\begin{array}{l}\text { Bryant et al. } \\
\text { [19] }\end{array}$ & PTSD & $\begin{array}{l}\text { fMRI: masked } \\
\text { fearful vs. neutral } \\
\text { faces }\end{array}$ & CBT (8 weekly sessions) & $\begin{array}{l}\text { PTSD: } 14 \\
\text { Healthy: } 14\end{array}$ & $\begin{array}{l}\text { CAPS Responders: } \geq 50 \% \\
\text { reduction in CAPS (7 R, } 7 \text { NR) }\end{array}$ & $\begin{array}{l}\text { Lower pre-treatment amygdala } \\
\text { and rACC activation predicted } \\
\text { greater improvement. }\end{array}$ \\
\hline $\begin{array}{l}\text { Nardo et al. } \\
{[69]}\end{array}$ & PTSD & $\mathrm{mMRI}$ & EMDR (5 sessions) & $\begin{array}{l}\text { PTSD: } 21 \\
\text { TENP: } 22\end{array}$ & $\begin{array}{l}\text { Responders: no longer met } \\
\text { diagnostic criteria (10 R, } 5 \text { NR) }\end{array}$ & $\begin{array}{l}R \text { had greater gray matter } \\
\text { density in the insula, } \\
\text { amygdala/parahippocampal } \\
\text { gyrus, posterior cingulate, and } \\
\text { middle, precentral, and dorsal } \\
\text { medial frontal gyri. }\end{array}$ \\
\hline $\begin{array}{l}\text { Whalen } \\
\text { et al. [75] }\end{array}$ & GAD & $\begin{array}{l}\text { fMRl: fearful vs. } \\
\text { neutral/happy } \\
\text { faces }\end{array}$ & $\begin{array}{l}\text { Venlafaxine ( } 8 \text { weeks; } \\
225 \text { mg/d max) }\end{array}$ & $\begin{array}{l}\text { GAD: } 15 \\
\text { Healthy: } 15\end{array}$ & HAM-A & $\begin{array}{l}\text { Lower pre-treatment amygdala } \\
\text { activation and greater rACC } \\
\text { activation predicted greater } \\
\text { improvement in anxiety. }\end{array}$ \\
\hline $\begin{array}{l}\text { Nitschke } \\
\text { et al. [73] }\end{array}$ & GAD & $\begin{array}{l}\text { fMRI: anticipation } \\
\text { of aversive vs. } \\
\text { neutral images }\end{array}$ & $\begin{array}{l}\text { Venlafaxine (8 weeks; } \\
225 \text { mg/d max) }\end{array}$ & $\begin{array}{l}\text { GAD: } 14 \\
\text { Healthy: } 12\end{array}$ & $\begin{array}{l}\text { HAM-A and Penn State } \\
\text { Worry Questionnaire }\end{array}$ & $\begin{array}{l}\text { Greater pre-treatment rACC } \\
\text { activation predicted greater } \\
\text { improvement in anxiety. }\end{array}$ \\
\hline $\begin{array}{l}\text { McClure } \\
\text { et al. [76] }\end{array}$ & GAD & $\begin{array}{l}\text { fMRl: fearful vs. } \\
\text { happy faces }\end{array}$ & $\begin{array}{l}\text { Fluoxetine ( } 8 \text { weeks; } \\
40 \text { mg/d max) or CBT ( } 8 \\
\text { weekly sessions) }\end{array}$ & $\begin{array}{l}\text { GAD: } 12 \\
\text { Fluoxetine: } 5 \\
\text { CBT: } 7\end{array}$ & CGl & $\begin{array}{l}\text { Greater pre-treatment } \\
\text { amygdala activation predicted } \\
\text { greater improvement. }\end{array}$ \\
\hline $\begin{array}{l}\text { Evans et al. } \\
\text { [87] }\end{array}$ & SAD & $\begin{array}{l}\text { PET-FDG: resting } \\
\text { state }\end{array}$ & $\begin{array}{l}\text { Tiagabine (6 weeks; } \\
16 \text { mg/d max) }\end{array}$ & $\begin{array}{l}\text { SAD: } 12 \\
\text { Healthy: } 10\end{array}$ & $\begin{array}{l}\text { LSAS Responders: } \geq 50 \% \\
\text { reduction in LSAS scores } \\
(7 \mathrm{R}, 5 \mathrm{NR})\end{array}$ & $\begin{array}{l}\text { Voxelwise correlations were } \\
\text { not significant. Pre-treatment } \\
\text { rCMRglu was lower in } \\
\text { subcallosal ACC in R compared } \\
\text { to healthy controls. }\end{array}$ \\
\hline $\begin{array}{l}\text { Doehrmann } \\
\text { et al. [13] }\end{array}$ & SAD & $\begin{array}{l}\text { fMRI: 1-back task, } \\
\text { angry vs. neutral } \\
\text { faces }\end{array}$ & CBT (12 weekly sessions) & SAD: 39 & LSAS & $\begin{array}{l}\text { Greater pre-treatment } \\
\text { activation in dorsal and ventral } \\
\text { occipitotemporal cortex } \\
\text { predicted greater } \\
\text { improvement. }\end{array}$ \\
\hline
\end{tabular}

$A C C$ anterior cingulate cortex, BT behavioral therapy, CAPS Clinician Administered PTSD Scale, CBT cognitive-behavioral therapy, CGI Clinical Global Impression scale, $E M D R$ eye movement desensitization and reprocessing, $f M R /$ functional magnetic resonance imaging, GAD generalized anxiety disorder, $H A M-A$ Hamilton Rating Scale for Anxiety, HAM-D Hamilton Rating Scale for Depression, LSAS Liebowitz Social Anxiety Scale, MDD major depressive disorder, mg/d milligrams per day, $m M R I$ morphometric magnetic resonance imaging, NR non-responders, OCD obsessive-compulsive disorder, OCR Obsessive Compulsive Rating scale, OFC orbitofrontal cortex, PET-FDG positron emission tomography with fluorodeoxyglucose, PET-015 positron emission tomography with oxygen-15, PTSD posttraumatic stress disorder, $R$ responders, $r A C C$ rostral anterior cingulate cortex, $r C B F$ regional cerebral blood flow, $r C M R g l u$ regional cerebral metabolic rate for glucose, SAD social anxiety disorder, SPECT single photon emission computed tomography, Ss subjects, TENP trauma-exposed non-PTSD, YBOCS Yale-Brown Obsessive-Compulsive Scale.

frontal cortex and the ACC, which may mediate intrusive thoughts and anxiety, respectively. Compulsions recruit the striatum to achieve thalamic gating, thereby neutralizing the obsessions and reducing anxiety. Indeed, several resting state and symptom provocation functional neuroimaging studies have revealed greater activation of the caudate, thalamus, orbitofrontal cortex, and/ or ACC in OCD (e.g., [25-28], although the direction of the abnormalities is not entirely uniform across studies). Pre-treatment functional abnormalities in these structures appear to resolve with successful treatment (e.g., [29-31]). Several studies have examined pre-treatment neuroimaging predictors of response to medication and/ or behavioral therapy (BT) or cognitive-behavioral therapy (CBT) in OCD.

\section{Medication}

In a very early PET study of OCD, Swedo and colleagues [32] found that pre-treatment rCMRglu in the right ACC and right orbitofrontal cortex was lower in clomipramine responders vs. non-responders. They also reported a positive correlation between pre-treatment symptom severity and pre-treatment rCMRglu in the orbitofrontal cortex, suggesting that treatment response is likely better in those participants with less severe symptoms. Saxena and colleagues [33] reported similar findings in a PET study of 
paroxetine. Specifically, lower pre-treatment rCMRglu in bilateral orbitofrontal cortex was associated with better improvement.

Another PET study of response to paroxetine [34] examined the more complicated question of whether pre-treatment rCMRglu could differentially predict improvement in OCD symptoms vs. depression symptoms in patients with OCD alone, comorbid OCD and MDD, and MDD alone. This study was unique in that it utilized both ROI-based and voxelwise analyses, the results of which were partially but not completely convergent. ROI-based analyses showed that greater pre-treatment rCMRglu in the caudate predicted greater improvement in OCD symptoms in the groups with OCD, but did not predict improvement in depression symptoms in any group. These findings were not replicated in the voxelwise analyses. ROI-based analyses also showed that lower pre-treatment rCMRglu in the amygdala predicted greater improvement in depression symptoms in the MDD group and in all subjects combined. Voxelwise analyses confirmed this finding in all subjects and further showed that greater pre-treatment rCMRglu in the medial frontal gyrus (just anterior to the rostral ACC [rACC]) predicted improvement in depression symptoms in all subjects regardless of diagnostic group. These findings are important because they suggest that (1) rCMRglu predictors of improvement differ for different types of symptoms even in the same subjects, and (2) rCMRglu predictors of improvement can cut across diagnostic lines.

Hendler et al. [35] used single photon emission computed tomography (SPECT) to determine whether pretreatment regional cerebral perfusion during symptom provocation could predict response to sertraline in individuals with OCD. Treatment responders showed lower pre-treatment perfusion in dorsal/caudal ACC and higher pre-treatment perfusion in right caudate compared to non-responders. These findings were not observed when the SPECT measures were obtained during the relaxed (unprovoked) state. Thus, these findings suggest that functional imaging-based measures obtained in one state (e.g., symptomatic) may predict treatment response in only that state and not others.

In contrast, Rauch and colleagues [36] found that state of the participants did not affect the prediction of response to fluvoxamine in OCD. In a PET study, these authors found that pre-treatment regional cerebral blood flow ( $\mathrm{rCBF}$ ) measured in neutral and symptomatic states similarly predicted treatment response: lower pre-treatment $\mathrm{rCBF}$ in orbitofrontal cortex and greater pre-treatment rCBF in the posterior cingulate cortex predicted better response to fluvoxamine.

Unlike previous studies of treatment response in OCD, Sanematsu and colleagues [37] used fMRI to examine neural predictors of improvement. Functional MRI data were collected while participants generated either words related to their OCD symptoms or control words (relating to flowers and vegetables). Greater pre-treatment activation in the right cerebellum and left superior temporal gyrus was associated with better response to fluvoxamine. Similarly, Ho Pian and colleagues [38] found that pretreatment activity (as measured by $99 \mathrm{mTc}-\mathrm{HMPAO}$ tracer uptake) in the cerebellum was greater in responders vs. non-responders to fluvoxamine.

In a study of OCD patients who were non-responders to SRIs, Buchsbaum and colleagues [39] found that responders to risperidone augmentation had lower pre-treatment rCMRglu in the striatum and higher pre-treatment rCMRglu in the ventral ACC. These findings differ from those of previous studies of OCD most likely because of the nature of both the patient group (SRI non-responders) and the treatment (antipsychotic augmentation).

\section{Medication and $B T / C B T$}

In what appears to be the first study to examine the neuroimaging predictors of response to two different treatments for OCD, Brody et al. [40] studied pre-treatment rCMRglu in patient groups who chose to receive either BT or fluoxetine. They found that greater pre-treatment rCMRglu in the left orbitofrontal cortex was significantly associated with greater symptomatic improvement after BT. Interestingly, within this same ROI, lower pretreatment rCMRglu was associated with greater improvement after treatment with fluoxetine.

In a similar study, Hoexter and colleagues [41] examined structural imaging predictors of treatment response in treatment-naïve patients randomly assigned to receive either fluoxetine or group CBT. Using voxel-based morphometry, they found that lower pre-treatment gray matter density in ventrolateral frontal cortex predicted greater improvement in OCD symptoms after treatment with fluoxetine. In contrast, greater pre-treatment gray matter density in subgenual ACC predicted greater improvement in OCD symptoms after CBT. When the two treatment groups were combined, there were no significant effects. Given that CBT involves extinction-like processes and that ventral medial prefrontal cortex (mPFC) is critical for the retention of extinction memory $[42,43]$, it makes sense that patients with greater pretreatment gray matter volume in ventral $\mathrm{mPFC}$ would show greater symptomatic improvement with CBT. Along with Brody et al. [40], this study suggests different imaging predictors of response to medication vs. CBT in OCD.

\section{Neurosurgery}

Identifying reliable and valid predictors of treatment response is even more critical when the treatment is 
invasive and associated with elevated risk, such as the case with neurosurgery. Rauch and colleagues [44] evaluated the PET predictors of response to anterior cingulotomy and found that relatively greater pretreatment rCMRglu in the posterior cingulate cortex predicted greater improvement in OCD symptom severity after surgery. These findings were consistent with those of Rauch et al. [36] in the prediction of response to fluvoxamine. In a study of anterior capsule stimulation, Van Laere and colleagues [45] found that greater pre-operative rCMRglu in the subgenual ACC predicted greater improvement in OCD symptom severity.

In summary, lower pre-treatment activity in the orbitofrontal cortex and greater activity in the caudate and posterior cingulate cortex predict a more favorable response to SRIs or neurosurgery in OCD. In contrast, greater pre-treatment activity or gray matter volume in ventral $\mathrm{mPFC}$ appears to predict better response to $\mathrm{BT} /$ CBT. This latter finding has also been reported in PTSD.

\section{Posttraumatic stress disorder (PTSD)}

Some neurocircuitry models $[46,47]$ posit that the amygdala is hyperresponsive in PTSD, perhaps accounting for hypervigilance, increased arousal, and the persistence of trauma-related memories. In addition, the mPFC (including the rACC) is thought to be hyporesponsive, with diminished inhibition over the amygdala, and this may underlie extinction memory deficits and difficulty ignoring trauma-related reminders. Neuroimaging studies of PTSD have generally reported increased activation in the amygdala, insular cortex, and dorsal anterior cingulate cortex (dACC), and decreased activation in the mPFC [48-51]. In addition, structural neuroimaging studies have reported decreased volume or gray matter density in the amygdala, $\mathrm{mPFC}$, and hippocampus in this disorder (e.g., [52-55]). Furthermore, PTSD symptom severity measures are often correlated positively with amygdala activation (e.g. [56,57]) and negatively with $\mathrm{mPFC}$ activation (e.g., [58-61]). A few studies have suggested that amygdala activation decreases and mPFC activation increases with successful treatment [62-65].

The use of exposure-based techniques to treat PTSD is well supported in the literature (e.g., $[66,67])$ and most studies that have examined neuroimaging predictors of treatment response have implemented such techniques. Bryant et al. [68] used structural MRI and voxel-based morphometry to determine whether pre-treatment gray matter density predicted response to CBT in participants with PTSD. Correlational analyses revealed that pretreatment gray matter density in the rACC was positively correlated with symptomatic improvement, even after controlling for depression and baseline PTSD symptom severity. Indeed, treatment responders, trauma-exposed comparison subjects without PTSD, and healthy comparison subjects had higher pre-treatment gray matter density in the rACC than did treatment non-responders.

In an fMRI study, Bryant and colleagues [19] presented backwardly-masked fearful vs. neutral facial expressions to participants with PTSD before they completed eight sessions of CBT. Treatment response was assessed 6 months after treatment completion. Voxelwise correlational analyses revealed that lower pre-treatment activation in the amygdala and rACC predicted better symptomatic improvement after CBT. Between-group comparisons (nonresponders vs. responders) confirmed these findings. Of note, the finding in the rACC was opposite of prediction.

In a voxel-based morphometry study of railway workers with PTSD, Nardo et al. [69] found that compared to nonresponders, responders to eye-movement desensitization and reprocessing (EMDR) treatment had greater pretreatment gray matter density in large territories of the brain including the insula, amygdala/parahippocampal gyrus, posterior cingulate, and middle, precentral, and dorsal medial frontal gyri.

In summary, pre-treatment neuroimaging measures of the amygdala and mPFC (specifically, the $\mathrm{rACC}$ ) predict response to $\mathrm{BT} / \mathrm{CBT}$ in PTSD, although additional studies are needed to specify the direction of the findings. Interestingly, mPFC activation also appears to predict treatment response in GAD, as shown below.

\section{Generalized anxiety disorder (GAD)}

Although relatively few functional neuroimaging studies of GAD exist in the literature, there has been some support for increased activation in the amygdala and mPFC in GAD relative to comparison groups ([70-73], but see also $[74,75])$. One study reported a positive correlation between amygdala activation and GAD symptom severity [72]. Three fMRI studies have examined neuroimaging predictors of treatment response in GAD.

Whalen and colleagues [75] found that pre-treatment activation in the amygdala in response to fearful (vs. neutral or happy) facial expressions was negatively correlated with symptomatic change after treatment with venlafaxine in GAD. Specifically, relatively lower pre-treatment amygdala responses were associated with relatively greater improvement. Interestingly, the opposite relationship was found in the rACC: the greater the pre-treatment rACC activation, the greater the improvement.

Using a different fMRI paradigm, Nitschke and colleagues [73] found that pre-treatment rACC activation during the anticipation of aversive and neutral pictures was inversely correlated with post-treatment symptoms of anxiety and worry (controlling for pre-treatment symptoms) in participants treated with venlafaxine. Thus, consistent with the findings of Whalen et al. [75], relatively greater pre-treatment rACC activation predicted relatively 
greater improvement. The authors found no significant association between pre-treatment amygdala responses and symptomatic change.

In contrast to the findings of Whalen et al. [75], McClure and colleagues [76] examined amygdala activation in twelve adolescents with anxiety disorders (nine had primary GAD) before treatment with either CBT or fluoxetine. Participants viewed fearful and happy faces in the scanner and responded to the question "How afraid are you?" Pre-treatment amygdala activation to fearful vs. happy faces was inversely associated with posttreatment symptom severity, even after controlling for pre-treatment symptom severity. That is, the greater the pretreatment amygdala activation, the better the treatment response. The discrepancy between this finding and that of Whalen et al. [75] could have been due to the younger age and/or the diagnostic heterogeneity in the McClure et al. sample (not all of the participants had GAD).

In summary, the amygdala and mPFC appear to predict treatment response in GAD, although the direction of the findings remains to be confirmed. Two of the three studies, however, suggest that greater pre-treatment mPFC (specifically, rACC) activation is related to better response to venlafaxine.

\section{Social anxiety disorder (SAD)}

Functional neuroimaging studies of SAD have revealed exaggerated amygdala activation (e.g. [77-79]), which is positively correlated with symptom severity (e.g., $[80,81]$ ) and appears to decrease after successful treatment $[82,83]$. Insular cortex also appears to be hyperresponsive in SAD relative to comparison groups (e.g., [84-86]). The direction of functional abnormalities in the mPFC in this disorder is less clear, with some studies reporting increased activation and others reporting decreased activation [51]. Only two studies have used neuroimaging measures to predict treatment response in SAD.

In a PET-FDG study, Evans and colleagues [87] found no significant voxelwise correlations between pretreatment rCMRglu in their regions of interest (which included mPFC/ACC, amygdala, hippocampus, parahippocampal gyrus, insula) and symptomatic improvement after treatment with tiagabine. However, categorical group comparisons revealed that treatment responders had lower pre-treatment rCMRglu in subcallosal gyrus compared to healthy control subjects. Furthermore, rCMRglu within this region was inversely correlated with symptomatic improvement across all treated participants (i.e., relatively lower pre-treatment rCMRglu was associated with relatively greater improvement). Treatment non-responders had lower baseline rCMRglu in the dACC than control subjects, but rCMRglu in the
dACC was not correlated with symptomatic improvement. It should be noted that the type of categorical group comparisons used in this study (i.e., responder vs. healthy controls and non-responder vs. healthy controls) differed from that of other studies (i.e., responder vs. non-responder) reviewed herein. This data analytic difference could very well account for discrepancies between the findings of this and other studies.

Doehrmann and colleagues [13] used fMRI to examine pre-treatment predictors of response to CBT in a relatively large sample $(n=39)$ of individuals with SAD. During scanning, participants performed a 1-back task on sets of visual stimuli that contained facial expressions (angry and neutral) and scenes without people (emotional and neutral). Correlational analyses showed that higher pre-treatment activation in dorsal and ventral regions of occipitotemporal cortex in response to angry vs. neutral faces was associated with greater symptomatic improvement. In multiple regression analyses predicting symptomatic improvement, the variance explained by the model was significantly greater when activation data from the dorsal and ventral occipitotemporal cortex were added over and above clinical measures such as pre-treatment symptom severity. Unlike previous findings reported in PTSD and GAD [19,75], amygdala activation did not significantly predict symptomatic improvement. This study appears to be the first to demonstrate the added benefit of neuroimaging measures over and above clinical measures in predicting treatment response in anxiety disorders. However, occipitotemporal cortex is not typically among the brain regions found to function abnormally in anxiety disorders.

In summary, only two studies have examined neuroimaging predictors of treatment response in SAD, and those two studies differed quite dramatically in terms of imaging methods, sample sizes, treatment type, and findings. This variability and paucity of data prevent us from drawing general conclusions about the neuroimaging predictors of treatment response in SAD at the present time.

\section{Conclusions}

In summary, although this literature is currently small, pre-treatment neuroimaging measures do appear to predict treatment response in anxiety disorders. Despite the variability in the findings within disorder categories, some consistent patterns have emerged. For example, in OCD, lower pre-treatment activity in the orbitofrontal cortex and greater activity in the caudate and posterior cingulate cortex appear to predict a more favorable response to treatment with SRIs or neurosurgery. In OCD, PTSD, and GAD, greater pre-treatment activity or gray matter density in the mPFC predicts better response to treatment (BT/CBT in OCD and PTSD, and venlafaxine 
in GAD). In PTSD and GAD, lower pre-treatment amygdala activation predicts a more favorable response to treatment (with CBT in PTSD and venlafaxine in GAD).

Consistent with neurocircuitry models of OCD (e.g., [23]), caudate activity predicted treatment response only in OCD and not in the other anxiety disorders examined herein. In contrast, mPFC neuroimaging measures predicted treatment response in all of the anxiety disorders examined, except for SAD (of which there are too few studies).

Confidence in these findings is tempered, however, by several limitations and caveats. First, as mentioned previously, the present literature is small and includes studies with relatively small numbers of subjects. Second, data analytic methods varied across studies and this alone could account for much of the variability in findings. Third, some studies did not appear to control for pre-treatment symptom severity, leaving open the question of whether neuroimaging measures are merely acting as proxies for baseline symptom severity in the prediction of treatment response. In order for neuroimaging measures to be practical in the prediction of treatment response, they would need to predict treatment response over and above the common clinical predictors, which are easier and less expensive to obtain. The findings of Doehrmann and colleagues [13] are especially encouraging in this regard. In our view, future studies should include regression analyses in which pre-treatment neuroimaging measures, baseline symptom severity, and other clinical (e.g., severity of comorbid disorders), psychophysiologic (e.g., heart rate responses), cognitive (e.g., response times on an interference task) and/or genotype measures are entered as predictors of treatment response (also measured continuously). These types of analyses benefit from the variability inherent in both the predictor and treatment response data and are potentially more powerful than comparisons between responders and nonresponders. Furthermore, the most accurate predictions of treatment response will likely result from the consideration of multiple types of predictors.

Fourth, because most studies did not use placebo control groups, it is possible that neuroimaging measures predict improvement in general rather than treatment response per se (as improvement could be due to expectancy effects). This may be less of a problem in studies that compared responders to non-responders if both groups had similar expectancies.

Fifth, most of the studies reviewed above predicted response to one type of treatment. While this is a necessary first step, future studies will need to include more than one treatment type $[40,41]$ in order to truly inform clinical decision-making.

Sixth, future studies will need to assess whether neuroimaging predictors of treatment response are specific to diagnostic categories. Furthermore, given the substantial comorbidity between anxiety disorders and depression, whether neuroimaging predictors of treatment response differ between these two diagnostic categories (and between comorbid and non-comorbid groups) will also need to be evaluated. A brief examination of the separate literatures reveals that some neuroimaging predictors of treatment response appear to be similar between anxiety disorders and depression (amygdala and rACC activation) $[88,89]$, but only one research group has actually examined these different diagnostic groups $(\mathrm{OCD}$, depression, and comorbid OCD/depression) in the same study [34].

Finally, arguably the most important big-picture question for future research to consider is whether the information gleaned from group studies (such as the ones described herein) can eventually be applied to clinical decision making in individual patients. Group studies could yield, for example, logistical regression equations or more complex classification schemes in which future individual patient data could be entered to predict a dichotomous treatment response outcome. This approach has been used in other areas of clinical research [90,91], but not yet in the current one. In the near future, machine learning data analytic techniques, which detect patterns in complex datasets in a bottom-up fashion, could potentially help discriminate between treatment responders and non-responders. Indeed, such techniques are already being used on neuroimaging data to discriminate between individuals with and without psychiatric disorder [92-95]. More generally, studies of neuroimaging predictors of treatment response could contribute to future clinical decision making in individual patients by identifying both (1) impaired neural circuits that could become targets of more directed (or adjunctive) treatments, and (2) other related biomarkers (e.g., skin conductance responses to conditioned stimuli or heart rate responses to loud tones) that may equally predict treatment response and are less expensive and/or more widely available than neuroimaging.

\section{Abbreviations}

ACC: Anterior cingulate cortex; BT: Behavioral therapy; CBT: Cognitive-behavioral therapy; dACC: Dorsal anterior cingulate cortex; fMRI: Functional magnetic resonance imaging; GAD: Generalized anxiety disorder; MPFC: Medial prefrontal cortex; OCD: Obsessive-compulsive disorder; PET: Positron emission tomography; PTSD: Posttraumatic stress disorder; rACC: Rostral anterior cingulate cortex; rCMRglu: Regional cerebral metabolic rate for glucose; rCBF: Regional cerebral blood flow; ROI: Region of interest; SPECT: Single photon emission computed tomography; SRI: Serotonin reuptake inhibitors.

\section{Competing interests}

The authors declare that they have no competing interests.

\section{Authors' contributions}

LMS read all studies reviewed herein and drafted the document. FCD, MBV, MKD, and SJD conducted literature searches and edited the document. All authors read and approved the final manuscript. 


\section{Acknowledgments}

The authors would like to thank Rachel Korus, Eliza White, and Lindsay Staples for their assistance in gathering the articles included in this review.

Received: 22 April 2013 Accepted: 19 June 2013

Published: 2 August 2013

\section{References}

1. Kessler RC, Berglund P, Demler O, Jin R, Merikangas KR, Walters EE: Lifetime prevalence and age-of-onset distributions of DSM-IV disorders in the National Comorbidity Survey Replication. Arch Gen Psychiatry 2005, 62(6):593-602.

2. Ahola K, Virtanen M, Honkonen T, Isometsa E, Aromaa A, Lonnqvist J: Common mental disorders and subsequent work disability: a population-based Health 2000 Study. J Affect Disord 2011, 134(1-3):365-372.

3. Cicek E, Cicek IE, Kayhan F, Uguz F, Kaya N: Quality of life, family burden and associated factors in relatives with obsessive-compulsive disorder. Gen Hosp Psychiatry 2013, 35(3):253-258.

4. Wedegaertner F, Arnhold-Kerri S, Sittaro NA, Bleich S, Geyer S, Lee WE: Depression- and anxiety-related sick leave and the risk of permanent disability and mortality in the working population in Germany: a cohort study. BMC Publ Health 2013, 13(1):145.

5. Mancebo MC, Eisen JL, Pinto A, Greenberg BD, Dyck IR, Rasmussen SA: The brown longitudinal obsessive compulsive study: treatments received and patient impressions of improvement. J Clin Psychiatry 2006, 67(11):1713-1720.

6. Ipser JC, Stein DJ: Evidence-based pharmacotherapy of post-traumatic stress disorder (PTSD). Int I Neuropsychopharmacol 2012, 15(6):825-840.

7. Hanrahan F, Field AP, Jones FW, Davey GC: A meta-analysis of cognitive therapy for worry in generalized anxiety disorder. Clin Psychol Rev 2013, 33(1):120-132.

8. Hofmann SG, Smits JA: Cognitive-behavioral therapy for adult anxiety disorders: a meta-analysis of randomized placebo-controlled trials. J Clin Psychiatry 2008, 69(4):621-632.

9. Tolin DF: Is cognitive-behavioral therapy more effective than other therapies? A meta-analytic review. Clin Psychol Rev 2010, 30(6):710-720.

10. Tukel R, Bozkurt O, Polat A, Genc A, Atli H: Clinical predictors of response to pharmacotherapy with selective serotonin reuptake inhibitors in obsessive-compulsive disorder. Psychiatry Clin Neurosci 2006, 60(4):404-409.

11. Connor KM, Hidalgo RB, Crockett B, Malik M, Katz RJ, Davidson JR: Predictors of treatment response in patients with posttraumatic stress disorder. Prog Neuropsychopharmacol Biol Psychiatry 2001, 25(2):337-345.

12. Karatzias A, Power K, McGoldrick T, Brown K, Buchanan R, Sharp D, Swanson $V$ : Predicting treatment outcome on three measures for post-traumatic stress disorder. Eur Arch Psychiatry Clin Neurosci 2007, 257(1):40-46.

13. Doehrmann O, Ghosh SS, Polli FE, Reynolds GO, Horn F, Keshavan A Triantafyllou C, Saygin ZM, Whitfield-Gabrieli S, Hofmann SG, et al: Predicting treatment response in social anxiety disorder from functional magnetic resonance imaging. JAMA Psychiatry 2013, 70(1):87-97.

14. Otto MW, Pollack MH, Gould RA, Worthington JJ 3rd, McArdle ET, Rosenbaum JF: A comparison of the efficacy of clonazepam and cognitive-behavioral group therapy for the treatment of social phobia. J Anxiety Disord 2000, 14(4):345-358.

15. Walkup JT, Labellarte MJ, Riddle MA, Pine D, Greenhill L, Klein R, Davies M, Sweeney M, Fu C, Abikoff H, et al: Searching for moderators and mediators of pharmacological treatment effects in children and adolescents with anxiety disorders. J Am Acad Child Adolesc Psychiatry 2003, 42(1):13-21.

16. Mataix-Cols D, Rauch SL, Manzo PA, Jenike MA, Baer L: Use of factoranalyzed symptom dimensions to predict outcome with serotonin reuptake inhibitors and placebo in the treatment of obsessivecompulsive disorder. Am J Psychiatry 1999, 156(9):1409-1416.

17. Baer L, Jenike MA, Black DW, Treece C, Rosenfeld R, Greist J: Effect of axis II diagnoses on treatment outcome with clomipramine in 55 patients with obsessive-compulsive disorder. Arch Gen Psychiatry 1992, 49(11):862-866.

18. Chambless DL, Tran GQ, Glass CR: Predictors of response to cognitivebehavioral group therapy for social phobia. J Anxiety Disord 1997, 11(3):221-240
19. Bryant RA, Felmingham K, Kemp A, Das P, Hughes G, Peduto A, Williams L: Amygdala and ventral anterior cingulate activation predicts treatment response to cognitive behaviour therapy for post-traumatic stress disorder. Psychol Med 2008, 38:555-561.

20. Bryant RA, Felmingham KL, Falconer EM, Pe Benito L, Dobson-Stone C, Pierce KD, Schofield PR: Preliminary evidence of the short allele of the serotonin transporter gene predicting poor response to cognitive behavior therapy in posttraumatic stress disorder. Biol Psychiatry 2010, 67(12):1217-1219.

21. Lee IS, Kim KJ, Kang EH, Yu BH: Beta-adrenoceptor affinity as a biological predictor of treatment response to paroxetine in patients with acute panic disorder. J Affect Disord 2008, 110(1-2):156-160.

22. Yehuda R, Bierer LM, Sarapas C, Makotkine I, Andrew R, Seckl JR: Cortisol metabolic predictors of response to psychotherapy for symptoms of PTSD in survivors of the World Trade Center attacks on September 11, 2001. Psychoneuroendocrinology 2009, 34(9):1304-1313.

23. Graybiel AM, Rauch SL: Toward a neurobiology of obsessive-compulsive disorder. Neuron 2000, 28(2):343-347.

24. Rauch S, Whalen P, Dougherty D, Jenike M: Neurobiological models of obsessive compulsive disorders. In Obsessive-compulsive disorders: practical management. edn. Edited by Jenike M, Baer L, Minichiello W. Boston: Mosby; 1998:222-253

25. Baxter LR Jr, Phelps ME, Mazziotta JC, Guze BH, Schwartz JM, Selin CE: Local cerebral glucose metabolic rates in obsessive-compulsive disorder. A comparison with rates in unipolar depression and in normal controls. Arch Gen Psychiatry 1987, 44(3):211-218.

26. Rauch SL, Jenike MA, Alpert NM, Baer L, Breiter HC, Savage CR, Fischman AJ: Regional cerebral blood flow measured during symptom provocation in obsessive-compulsive disorder using oxygen 15-labeled carbon dioxide and positron emission tomography. Arch Gen Psychiatry 1994, 51(1):62-70.

27. Rotge JY, Guehl D, Dilharreguy B, Cuny E, Tignol J, Bioulac B, Allard M, Burbaud P, Aouizerate B: Provocation of obsessive-compulsive symptoms: a quantitative voxel-based meta-analysis of functional neuroimaging studies. J Psychiatry Neurosci 2008, 33(5):405-412.

28. Whiteside SP, Port JD, Abramowitz JS: A meta-analysis of functional neuroimaging in obsessive-compulsive disorder. Psychiatry Res 2004, 132(1):69-79.

29. Baxter LR Jr, Schwartz JM, Bergman KS, Szuba MP, Guze BH, Mazziotta JC Alazraki A, Selin CE, Ferng HK, Munford P, et al: Caudate glucose metabolic rate changes with both drug and behavior therapy for obsessivecompulsive disorder. Arch Gen Psychiatry 1992, 49(9):681-689.

30. Saxena S, Gorbis E, O'Neill J, Baker SK, Mandelkern MA, Maidment KM, Chang S, Salamon N, Brody AL, Schwartz JM, et al: Rapid effects of brief intensive cognitive-behavioral therapy on brain glucose metabolism in obsessive-compulsive disorder. Mol Psychiatry 2009, 14(2):197-205.

31. Schwartz JM, Stoessel PW, Baxter LR Jr, Martin KM, Phelps ME: Systematic changes in cerebral glucose metabolic rate after successful behavior modification treatment of obsessive-compulsive disorder. Arch Gen Psychiatry 1996, 53(2):109-113.

32. Swedo SE, Schapiro MB, Grady CL, Cheslow DL, Leonard HL, Kumar A, Friedland R, Rapoport SI, Rapoport JL: Cerebral glucose metabolism in childhood-onset obsessive-compulsive disorder. Arch Gen Psychiatry 1989, 46(6):518-523

33. Saxena S, Brody AL, Maidment KM, Dunkin JJ, Colgan M, Alborzian S, Phelps $M E$, Baxter LR Jr: Localized orbitofrontal and subcortical metabolic changes and predictors of response to paroxetine treatment in obsessive-compulsive disorder. Neuropsychopharmacology 1999, 21(6):683-693.

34. Saxena S, Brody AL, Ho ML, Zohrabi N, Maidment KM, Baxter LR Jr: Differential brain metabolic predictors of response to paroxetine in obsessive-compulsive disorder versus major depression. Am J Psychiatry 2003, 160(3):522-532.

35. Hendler T, Goshen E, Tzila Zwas S, Sasson Y, Gal G, Zohar J: Brain reactivity to specific symptom provocation indicates prospective therapeutic outcome in OCD. Psychiatry Res 2003, 124(2):87-103.

36. Rauch SL, Shin LM, Dougherty DD, Alpert NM, Fischman AJ, Jenike MA: Predictors of fluvoxamine response in contamination-related obsessive compulsive disorder: a PET symptom provocation study. Neuropsychopharmacology 2002, 27(5):782-791

37. Sanematsu H, Nakao T, Yoshiura T, Nabeyama M, Togao O, Tomita M, Masuda Y, Nakatani E, Nakagawa A, Kanba S: Predictors of treatment 
response to fluvoxamine in obsessive-compulsive disorder: an fMRI study. J Psychiatr Res 2010, 44(4):193-200.

38. Ho Pian KL, van Megen HJ, Ramsey NF, Mandl R, van Rijk PP, Wynne HJ, Westenberg HG: Decreased thalamic blood flow in obsessive-compulsive disorder patients responding to fluvoxamine. Psychiatry Res 2005, 138(2):89-97.

39. Buchsbaum MS, Hollander E, Pallanti S, Baldini Rossi N, Platholi J, Newmark R, Bloom R, Sood E: Positron emission tomography imaging of risperidone augmentation in serotonin reuptake inhibitor-refractory patients. Neuropsychobiology 2006, 53(3):157-168.

40. Brody AL, Saxena S, Schwartz JM, Stoessel PW, Maidment K, Phelps ME, Baxter LR Jr: FDG-PET predictors of response to behavioral therapy and pharmacotherapy in obsessive compulsive disorder. Psychiatry Res 1998, 84(1):1-6

41. Hoexter MQ, Dougherty DD, Shavitt RG, D'Alcante CC, Duran FL, Lopes AC, Diniz JB, Batistuzzo MC, Evans KC, Bressan RA, et al: Differential prefrontal gray matter correlates of treatment response to fluoxetine or cognitivebehavioral therapy in obsessive-compulsive disorder. European Neuropsychopharmacology: The Journal of the European College of Neuropsychopharmacology 2013, 23(7):569-580

42. Milad MR, Quinn BT, Pitman RK, Orr SP, Fischl B, Rauch SL: Thickness of ventromedial prefrontal cortex in humans is correlated with extinction memory. Proc Natl Acad Sci USA 2005, 102(30):10706-10711.

43. Milad MR, Wright Cl, Orr SP, Pitman RK, Quirk GJ, Rauch SL: Recall of fear extinction in humans activates the ventromedial prefrontal cortex and hippocampus in concert. Biol Psychiatry 2007, 62(5):446-454.

44. Rauch SL, Dougherty DD, Cosgrove GR, Cassem EH, Alpert NM, Price BH, Nierenberg AA, Mayberg HS, Baer L, Jenike MA, et al: Cerebral metabolic correlates as potential predictors of response to anterior cingulotomy for obsessive compulsive disorder. Biol Psychiatry 2001, 50(9):659-667.

45. Van Laere K, Nuttin B, Gabriels L, Dupont P, Rasmussen S, Greenberg BD, Cosyns P: Metabolic imaging of anterior capsular stimulation in refractory obsessive-compulsive disorder: a key role for the subgenual anterior cingulate and ventral striatum. J Nucl Med 2006, 47(5):740-747.

46. Rauch SL, Shin LM, Whalen PJ, Pitman RK: Neuroimaging and the neuroanatomy of PTSD. CNS Spectrums 1998, 3(suppl. 2):30-41.

47. Rauch SL, Shin LM, Phelps EA: Neurocircuitry models of posttraumatic stress disorder and extinction: human neuroimaging research-past, present, and future. Biol Psychiatry 2006, 60(4):376-382

48. Hayes JP, Hayes SM, Mikedis AM: Quantitative meta-analysis of neural activity in posttraumatic stress disorder. Biol Mood Anxiety Disord 2012, 2(1):9.

49. Etkin A, Wager TD: Functional neuroimaging of anxiety: a meta-analysis of emotional processing in PTSD, social anxiety disorder, and specific phobia. Am J Psychiatry 2007, 164(10):1476-1488.

50. Patel R, Spreng RN, Shin LM, Girard TA: Neurocircuitry models of posttraumatic stress disorder and beyond: a meta-analysis of functional neuroimaging studies. Neurosci Biobehav Rev 2012, 36(9):2130-2142.

51. Shin LM, Liberzon I: The neurocircuitry of fear, stress, and anxiety disorders. Neuropsychopharmacology 2010, 35(1):169-191.

52. Morey RA, Gold AL, LaBar KS, Beall SK, Brown VM, Haswell CC, Nasser JD, Wagner HR, McCarthy G: Amygdala volume changes in posttraumatic stress disorder in a large case-controlled veterans group. Arch Gen Psychiatry 2012, 69(11):1169-1178.

53. Karl A, Schaefer M, Malta LS, Dorfel D, Rohleder N, Werner A: A metaanalysis of structural brain abnormalities in PTSD. Neurosci Biobehav Rev 2006, 30(7):1004-1031.

54. Rauch SL, Shin LM, Segal E, Pitman RK, Carson MA, McMullin K, Whalen PJ, Makris N: Selectively reduced regional cortical volumes in post-traumatic stress disorder. Neuroreport 2003, 14(7):913-916.

55. Woodward SH, Kaloupek DG, Streeter CC, Martinez C, Schaer M, Eliez S: Decreased anterior cingulate volume in combat-related PTSD. Biol Psychiatry 2006, 59(7):582-587.

56. Armony JL, Corbo V, Clement $\mathrm{MH}$, Brunet $\mathrm{A}$ : Amygdala response in patients with acute PTSD to masked and unmasked emotional facial expressions. Am J Psychiatry 2005, 162(10):1961-1963.

57. Rauch SL, Whalen PJ, Shin LM, Mclnerney SC, Macklin ML, Lasko NB, Orr SP, Pitman RK: Exaggerated amygdala response to masked facial stimuli in posttraumatic stress disorder: a functional MRI study. Biol Psychiatry 2000, 47(9):769-776.

58. Britton JC, Phan KL, Taylor SF, Fig LM, Liberzon I: Corticolimbic blood flow in posttraumatic stress disorder during script-driven imagery. Biol Psychiatry 2005, 57(8):832-840.
59. Kim MJ, Chey J, Chung A, Bae S, Khang H, Ham B, Yoon SJ, Jeong DU, Lyoo IK Diminished rostral anterior cingulate activity in response to threat-related events in posttraumatic stress disorder. J Psychiatr Res 2008, 42(4):268-277.

60. Shin LM, Orr SP, Carson MA, Rauch SL, Macklin ML, Lasko NB, Marzol Peters $P$, Metzger L, Dougherty DD, Cannistraro PA, et al: Regional cerebral blood flow in amygdala and medial prefrontal cortex during traumatic imagery in male and female Vietnam veterans with PTSD. Arch Gen Psychiatry 2004, 61(2):168-176.

61. Shin LM, Wright Cl, Cannistraro PA, Wedig MM, McMullin K, Martis B, Macklin ML, Lasko NB, Cavanagh SR, Krangel TS, et al: A functional magnetic resonance imaging study of amygdala and medial prefrontal cortex responses to overtly presented fearful faces in posttraumatic stress disorder. Arch Gen Psychiatry 2005, 62(3):273-281.

62. Felmingham K, Kemp A, Williams L, Das P, Hughes G, Peduto A, Bryant R: Changes in anterior cingulate and amygdala after cognitive behavior therapy of posttraumatic stress disorder. Psychol Sci 2007, 18(2):127-129.

63. Lansing K, Amen DG, Hanks C, Rudy L: High-resolution brain SPECT imaging and eye movement desensitization and reprocessing in police officers with PTSD. J Neuropsychiatry Clin Neurosci 2005, 17(4):526-532

64. Peres JF, Newberg AB, Mercante JP, Simao M, Albuquerque VE, Peres MJ, Nasello AG: Cerebral blood flow changes during retrieval of traumatic memories before and after psychotherapy: a SPECT study. Psychol Med 2007, 37(10):1481-1491.

65. Seedat S, Warwick J, van Heerden B, Hugo C, Zungu-Dirwayi N, Van Kradenburg J, Stein DJ: Single photon emission computed tomography in posttraumatic stress disorder before and after treatment with a selective serotonin reuptake inhibitor. J Affect Disord 2004, 80(1):45-53.

66. Cukor J, Spitalnick J, Difede J, Rizzo A, Rothbaum BO: Emerging treatments for PTSD. Clin Psychol Rev 2009, 29(8):715-726.

67. Hembree EA, Foa EB: Posttraumatic stress disorder: psychological factors and psychosocial interventions. J Clin Psychiatry 2000, 61(Suppl 7):33-39.

68. Bryant RA, Felmingham K, Whitford TJ, Kemp A, Hughes G, Peduto A, Williams LM: Rostral anterior cingulate volume predicts treatment response to cognitive-behavioural therapy for posttraumatic stress disorder. J Psychiatry Neurosci 2008, 33(2):142-146.

69. Nardo D, Hogberg G, Looi JC, Larsson S, Hallstrom T, Pagani M: Gray matter density in limbic and paralimbic cortices is associated with trauma load and EMDR outcome in PTSD patients. J Psychiatr Res 2010, 44(7):477-485.

70. Krain AL, Gotimer K, Hefton S, Ernst M, Castellanos FX, Pine DS, Milham MP: A functional magnetic resonance imaging investigation of uncertainty in adolescents with anxiety disorders. Biol Psychiatry 2008, 63(6):563-568.

71. McClure EB, Monk CS, Nelson EE, Parrish JM, Adler A, Blair RJ, Fromm S, Charney DS, Leibenluft E, Ernst $M$, et al: Abnormal attention modulation of fear circuit function in pediatric generalized anxiety disorder. Arch Gen Psychiatry 2007, 64(1):97-106.

72. Monk CS, Telzer EH, Mogg K, Bradley BP, Mai X, Louro HM, Chen G, McClure-Tone EB, Ernst M, Pine DS: Amygdala and ventrolateral prefrontal cortex activation to masked angry faces in children and adolescents with generalized anxiety disorder. Arch Gen Psychiatry 2008, 65(5):568-576.

73. Nitschke JB, Sarinopoulos I, Oathes DJ, Johnstone T, Whalen PJ, Davidson RJ, Kalin $\mathrm{NH}$ : Anticipatory activation in the amygdala and anterior cingulate in generalized anxiety disorder and prediction of treatment response. Am J Psychiatry 2009, 166(3):302-310.

74. Blair K, Shaywitz J, Smith BW, Rhodes R, Geraci M, Jones M, McCaffrey D, Vythilingam M, Finger E, Mondillo K, et al: Response to emotional expressions in generalized social phobia and generalized anxiety disorder: evidence for separate disorders. Am J Psychiatry 2008, 165(9):1193-1202.

75. Whalen PJ, Johnstone T, Somerville LH, Nitschke JB, Polis S, Alexander AL, Davidson RJ, Kalin NH: A functional magnetic resonance imaging predictor of treatment response to venlafaxine in generalized anxiety disorder. Biol Psychiatry 2008, 63(9):858-863.

76. McClure EB, Adler A, Monk CS, Cameron J, Smith S, Nelson EE, Leibenluft E, Ernst M, Pine DS: fMRI predictors of treatment outcome in pediatric anxiety disorders. Psychopharmacology (Berl) 2007, 191(1):97-105.

77. Phan KL, Fitzgerald DA, Nathan PJ, Tancer ME: Association between amygdala hyperactivity to harsh faces and severity of social anxiety in generalized social phobia. Biol Psychiatry 2006, 59(5):424-429.

78. Stein MB, Goldin PR, Sareen J, Zorrilla LT, Brown GG: Increased amygdala activation to angry and contemptuous faces in generalized social phobia. Arch Gen Psychiatry 2002, 59(11):1027-1034. 
79. Tillfors M, Furmark T, Marteinsdottir I, Fredrikson M: Cerebral blood flow during anticipation of public speaking in social phobia: a PET study. Biol Psychiatry 2002, 52(11):1113-1119.

80. Evans KC, Wright Cl, Wedig MM, Gold AL, Pollack MH, Rauch SL: A functional MRI study of amygdala responses to angry schematic faces in social anxiety disorder. Depress Anxiety 2008, 25(6):496-505.

81. Guyer AE, Lau JY, McClure-Tone EB, Parrish J, Shiffrin ND, Reynolds RC, Chen G, Blair RJ, Leibenluft E, Fox NA, et al: Amygdala and ventrolateral prefrontal cortex function during anticipated peer evaluation in pediatric social anxiety. Arch Gen Psychiatry 2008, 65(11):1303-1312.

82. Furmark T, Tillfors M, Marteinsdottir I, Fischer H, Pissiota A, Langstrom B, Fredrikson M: Common changes in cerebral blood flow in patients with social phobia treated with citalopram or cognitive-behavioral therapy. Arch Gen Psychiatry 2002, 59(5):425-433.

83. Furmark T, Appel L, Michelgard A, Wahlstedt K, Ahs F, Zancan S, Jacobsson E, Flyckt K, Grohp M, Bergstrom M, et al: Cerebral blood flow changes after treatment of social phobia with the neurokinin-1 antagonist GR205171, citalopram, or placebo. Biol Psychiatry 2005, 58(2):132-142.

84. Amir N, Klumpp H, Elias J, Bedwell JS, Yanasak N, Miller LS: Increased activation of the anterior cingulate cortex during processing of disgust faces in individuals with social phobia. Biol Psychiatry 2005, 57(9):975-981.

85. Lorberbaum JP, Kose S, Johnson MR, Arana GW, Sullivan LK, Hamner MB, Ballenger JC, Lydiard RB, Brodrick PS, Bohning DE, et al: Neural correlates of speech anticipatory anxiety in generalized social phobia. Neuroreport 2004, 15(18):2701-2705.

86. Straube T, Kolassa IT, Glauer M, Mentzel HJ, Miltner WH: Effect of task conditions on brain responses to threatening faces in social phobics: an event-related functional magnetic resonance imaging study. Biol Psychiatry 2004, 56(12):921-930.

87. Evans KC, Simon NM, Dougherty DD, Hoge EA, Worthington JJ, Chow C, Kaufman RE, Gold AL, Fischman AJ, Pollack MH, et al: A PET study of tiagabine treatment implicates ventral medial prefrontal cortex in generalized social anxiety disorder. Neuropsychopharmacology 2009, 34(2):390-398.

88. Fu CH, Steiner H, Costafreda SG: Predictive neural biomarkers of clinical response in depression: A meta-analysis of functional and structural neuroimaging studies of pharmacological and psychological therapies. Neurobiol Dis 2013, 52:75-83.

89. Mayberg HS, Brannan SK, Mahurin RK, Jerabek PA, Brickman JS, Tekell JL, Silva JA, McGinnis S, Glass TG, Martin CC, et al: Cingulate function in depression: a potential predictor of treatment response. Neuroreport 1997, 8(4):1057-1061.

90. Keane TM, Kolb LC, Kaloupek DG, Orr SP, Blanchard EB, Thomas RG, Hsieh FY, Lavori PW: Utility of psychophysiological measurement in the diagnosis of posttraumatic stress disorder: results from a Department of Veterans Affairs Cooperative Study. J Consult Clin Psychol 1998, 66(6):914-923.

91. Siegle GJ, Thompson WK, Collier A, Berman SR, Feldmiller J, Thase ME, Friedman ES: Toward clinically useful neuroimaging in depression treatment: prognostic utility of subgenual cingulate activity for determining depression outcome in cognitive therapy across studies, scanners, and patient characteristics. Arch Gen Psychiatry 2012, 69(9):913-924.

92. Gong Q, Li L, Tognin S, Wu Q, Pettersson-Yeo W, Lui S, Huang X, Marquand AF, Mechelli A: Using structural neuroanatomy to identify trauma survivors with and without post-traumatic stress disorder at the individual level. Psychol Med 2013:1-9. epub ahead of print.

93. Pettersson-Yeo W, Benetti S, Marquand AF, Dell'acqua F, Williams SC, Allen P, Prata D, McGuire P, Mechelli A: Using genetic, cognitive and multi-modal neuroimaging data to identify ultra-high-risk and first-episode psychosis at the individual level. Psychol Med 2013:1-16. epub ahead of print.

94. Tang $Y$, Jiang $W$, Liao J, Wang W, Luo A: Identifying individuals with antisocial personality disorder using resting-state FMRI. PLoS One 2013, 8(4):e60652.

95. Zeng LL, Shen H, Liu L, Hu D: Unsupervised classification of major depression using functional connectivity MRI. Hum Brain Mapp 2013. epub ahead of print.

doi:10.1186/2045-5380-3-15

Cite this article as: Shin et al:: Neuroimaging predictors of treatment response in anxiety disorders. Biology of Mood \& Anxiety Disorders 2013 3:15.

\section{Submit your next manuscript to BioMed Central and take full advantage of:}

- Convenient online submission

- Thorough peer review

- No space constraints or color figure charges

- Immediate publication on acceptance

- Inclusion in PubMed, CAS, Scopus and Google Scholar

- Research which is freely available for redistribution 